\title{
Effect of n-3 long-chain polyunsaturated fatty acids on wound healing using animal models - a review
}

\author{
Tomáš Komprda \\ Mendel University in Brno, Department of Food Technology, Brno, Czech Republic
}

Received April 11, 2018

Accepted December 7, 2018

\begin{abstract}
The present review summarizes results of experiments, mostly performed on rodents, regarding the effects of fish oil (FO) and its biologically active constituents, eicosapentaenoic acid (EPA) and docosahexaenoic acid (DHA), on the healing of cutaneous wounds, but also of selected other types of injury. Structure, metabolism and functions of EPA/DHA in an organism are briefly mentioned, with an emphasis on the ability of these long-chain polyunsaturated fatty acids to modulate inflammation. Wound healing as a complex programmed sequence of cellular and molecular processes including inflammation, cell migration, angiogenesis, synthesis of provisional matrix, collagen deposition and reepithelialisation is briefly described. Markers for evaluation of the healing process include planimetry indices, tensile strength, quantification of collagen synthesis including hydroxyproline determination, histopathology/immunohistochemistry and genomic/ proteomic markers. As far as effects on wound healing are concerned, the main emphasis is put on the outcomes of experiments using a dietary FO/DHA/EPA administration, but the results of experiments with a parenteral application are also mentioned, together with selected relevant in vitro studies. An important conclusion from the above-mentioned studies is an inconsistency of FO/DHA/EPA effects on wound healing: decreased/increased collagen deposition; lower/higher counts of the inflammatory cells in the healing tissue; increased/decreased concentration of both pro- and anti-inflammatory cytokines; DHA accelerated/delayed wound healing process. Some experiments indicate superiority of DHA over EPA regarding wound healing.
\end{abstract}

Hydroxyproline, inflammation, interleukins, rodents, docosahexaenoic acid, fish oil

The present review deals with the effects of n-3 long-chain polyunsaturated fatty acids (LC-PUFA) in animal (especially rodent) models, the results of these experiments being also relevant to human health. Positive effects of n-3 LC-PUFA, especially eicosapentaenoic acid (EPA) and docosahexaenoic acid (DHA), on human health have been reported in cardiovascular diseases (Givens and Gibbs 2008), autoimmune diseases (Zárate et al. 2017), foetal and neonatal brain development (Ruxton et al. 2005), dementia (BarbergerGateau et al. 2002), cognitive function (van Gelder et al. 2007) and wound healing (McDaniel et al. 2008). From these varied topics, the present review deals selectively with the potential of EPA and DHA (fish oil) to modulate particular phases of wound healing, especially (but not exclusively) cutaneous wound healing.

\section{Long-chain polyunsaturated fatty acids n-3}

Structure, metabolism, functions in an organism

In a mammalian organism, LC-PUFA n-3 (first double bond comes from the third carbon from the methyl end of the molecule), such as EPA (20:5 n-3), docosapentaenoic acid (DPA, 22:5 n-3) or DHA (22:6n-3) can be synthetized from $\alpha$-linolenic acid (ALA; 18:3 $n-3$ ) by the action of desaturases and elongases (Das 2006; Jump 2008). The LC-PUFA n-3 are important components of the cell membranes (Das 2006), where they influence

Address for correspondence:

Tomáš Komprda

Department of Food Technology

Mendel University in Brno

Zemědělská 1, 61300 Brno, Czech Republic

Phone: +420 545133261

E-mail: komprda@mendelu.cz

http://actavet.vfu.cz/ 
membrane fluidity and behaviour of the integral membrane proteins and participate in regulation of many functions in the organism, including regulation of an inflammatory response (Schmitz and Ecker 2008), which is one of several overlapping phases of wound healing (Caetano et al. 2016).

Metabolism of n-3 PUFA in the mammalian organism should be considered together with metabolism of the n-6 group of PUFA originating in linoleic acid (LA; 18:2 n-6). Physiologically the most important metabolite of the n-6 group is arachidonic acid (AA; 20:4 n-6; Zárate et al. 2017). The key metabolites of both EPA and AA (together called eicosanoids) are endoperoxides, such as thromboxanes and prostaglandins produced under catalysis of cyclooxygenase on the one hand, and leukotrienes produced by an action of 5-lipoxygenase on the other hand (Nakamura et al. 2004; Das 2006; Jump 2008).

Eicosanoids produced from AA increase the tendency of thrombocytes to aggregate, act mostly as vasoconstrictors and have predominantly pro-inflammatory effects. EPA-derived eicosanoids have less pronounced and in many instances opposite effects in comparison with their AA-derived counterparts (Das 2006); inflammation modulating effect of EPA/DHA can make a difference especially in the initial phases of wound healing (McDaniel et al. 2008).

Functions of EPA/DHA on a molecular level are based (among others) on modulation of the signalling pathways mediated by transcription factors nuclear factor kappa B (NF-kB; Kostadinova et al. 2005), peroxisome proliferator-activated receptors (PPARs; Arai et al. 2009) and sterol response-element-binding protein (SREBP; Nakamura et al. 2004; Jump 2008). Especially NF- $\kappa B$ and PPAR $\gamma$ are involved in signalling during the inflammation phase of wound healing. Inflammation is a relatively short part of the wound healing process, but its proper course is decisive from the viewpoint of a successful tissue remodelling and scar tissue formation (Otranto et al. 2010). Therefore the next part of the review is devoted to the evaluation of an EPA/DHA capability to modulate inflammation.

\section{LC-PUFA n-3 as inflammation modulators}

Anti-inflammatory effects of EPA and DHA are based, among others, on the competition with AA in eicosanoid synthesis (Schmitz and Ecker 2008) and on modulation of signalling pathways mediated by transcription factors PPAR $\alpha, \operatorname{PPAR} \gamma$ and NF- $\mathrm{BB}$ (Komprda 2012).

EPA and DHA are endogenous ligands of PPAR $\gamma$, whose activation increases the amount of the adipose tissue-derived anti-inflammatory hormone adiponectin (Siriwardhana et al. 2013). The EPA/DHA anti-inflammatory effect is further mediated by GPR120, a G-protein coupled receptor, whose activation leads to a repression of the macrophageinduced inflammation (Flock et al. 2013). According to Oliver et al. (2010), EPA/DHA decreases plasma levels of pro-inflammatory markers interleukin 6 (IL-6), tumour necrosis factor alpha (TNF- $\alpha)$ or interferon $\gamma$ (IFN- $\gamma)$, and increases the concentration of antiinflammatory markers IL-10 and transforming growth factor beta (TGF- $\beta$ ).

During the acute inflammatory response, neutrophils are first to arrive at the site of inflammation and play an important protective role in innate immunity and host defence; however, excessive accumulation of neutrophils within the tissue can lead to tissue damage and amplification of the inflammatory response (Arita et al. 2005). Lipid mediators, such as prostaglandins and leukotrienes play pivotal roles in the initiation of acute inflammation, whereas resolvins and protectins, inflammation mediators derived from LC-PUFA n-3 (Serhan et al. 2015), promote and stimulate the active resolution of inflammation (Serhan and Savill 2005). The control of neutrophil infiltration is of wide interest in this situation, which underlines the importance of the above-mentioned resolvins and protectins (Dinarello 2010); resolution of acute inflammation is a central component of host defence and the return of tissue to homeostasis (Serhan et al. 2015). As an example, EPA-derived 
resolvin E1 reduced leukocyte infiltration in a mouse peritonitis model and protected against the development of induced colitis, including decreased leukocyte infiltration and pro-inflammatory gene expression in a study by Arita et al. (2005).

As far as in vitro experiments are concerned, EPA and DHA decreased lipopolysaccharide (LPS)-induced pro-inflammatory IL-1 $\beta$ expression in 3T3-L1 adipocytes (Cranmer-Byng et al. 2015); Romacho et al. (2015) reported prevention of NF- $\mathrm{KB}$ activation (induced by TNF- $\alpha$ ) in human primary adipocytes by EPA/DHA; DHA decreased degree of monocyte chemoattractant protein-1 and IL-6 secreted from murine adipocytes in an experiment of De Boer et al. (2014).

Regarding in vivo experiments, fish oil (rich source of EPA) tended to reduce IL-1 $\beta$ and IL-12 production in LPS-challenged pigs (Liu et al. 2003), and n-3 PUFA intervention in LPS-challenged mice decreased levels of pro-inflammatory cytokines, including TNF- $\alpha$ (Liu et al. 2015). However, Hall et al. (2012) reported no substantial effect of fish oil (EPA and DHA) on pro-inflammatory cytokines in rodents. Similarly, Vigerust et al. (2013) found no significant differences between fish oil-fed and control animals in the hepatic concentrations of IFN- $\gamma$, IL-1 $\beta$, IL-2 or IL-6; and the content of pro-inflammatory IL-17 was even higher in the fish oil group.

An equivocal effect of fish oil on inflammatory markers was confirmed by Komprda et al. (2018) who reported a higher concentration of both anti-inflammatory IL-4 and pro-inflammatory TNF- $\alpha$ in plasma of fish oil-fed LPS-challenged pigs in comparison with the palm oil-fed controls. A diet rich in DHA did not affect the amount of the nuclear (i.e. active) fraction of NF- $\kappa \mathrm{B}$, but nevertheless increased the plasma level of anti-inflammatory TGF- $\beta 1$ in rats with an induced state of a low-grade inflammation (Komprda et al. 2016). This part of the review can be concluded by stating that LC-PUFA n-3 have an equivocal effect on inflammation and thus on the subsequent stages of wound healing.

\section{Wound healing}

\section{Definition and phases}

Wound healing is generally defined as the process by which a body tissue (usually skin) repairs itself after trauma, a dynamic process aimed at restoring the structure of the injured tissue (Caetano et al. 2016). It is a sequential process that occurs in three overlapping stages: inflammation, cell proliferation and tissue remodelling (Gurtner et al. 2008), resulting in scar tissue formation (Otranto et al. 2010). Some authors divide wound healing into four phases: inflammation, coagulation, tissue formation and tissue remodelling (Caetano et al. 2016). This complex programmed sequence of cellular and molecular processes includes inflammation, cell migration, angiogenesis, synthesis of provisional matrix, collagen deposition and reepithelialisation (Gercek et al. 2007). From the viewpoint of regenerative veterinary/human medicine and a new field of tissue engineering, the process of wound healing can be divided into two major phases: the early phase and the cellular phase: the early phase leads to haemostasis and formation of a makeshift extracellular matrix, the cellular phase involves an inflammatory response, synthesis of the granulation tissue and restoration of the epithelial layer (Nguyen et al. 2009).

Immediately after injury, platelets start to release cytokines and growth factors that recruit inflammatory cells and pro-inflammatory factors (serotonin, bradykinin, prostaglandins, thromboxanes, histamine) to stimulate local debridement, to degrade foreign particles and to provide provisional matrix for further proliferation of fibroblasts leading to formation of granulation tissue (Gurtner et al. 2008; Velnar et al. 2009).

The following phase is characterized by the formation of granulation tissue. Fibroblasts proliferate and migrate to the damaged tissue area in order to synthetize the new 
extracellular matrix elements (Velnar et al. 2009; Guo and Dipietro 2010; Caetano et al. 2016), such as proteoglycans, glycosaminoglycans and collagen, which are deposited in the damaged area, where they replace the initial provisional matrix, comprised of fibrin (Campos et al. 2008; Velnar et al. 2009). The major structural component of granulation tissue, strengthening the extracellular matrix, is collagen, with an important constituent amino-acid proline, and hydroxyproline as a biochemical marker for collagen and an indicator of the progression of healing (Caetano et al. 2016).

When using animal (usually rodent) models for wound healing in humans, it is important to realize that while the closure of human wounds is primarily accomplished through proliferation and migration of cells at the wound edge, contraction is the driving force behind wound closure in rodents (Pensalfini et al. 2018). Nevertheless, the major cellular and molecular processes that occur during healing are conserved between both species and allow for rodent wounds to serve as a model for human wound repair (Galiano et al. 2004; Gurtner et al. 2008).

\section{Markers for evaluation of the healing process}

\section{Planimetry (rate of healing)}

To quantitate wound contraction and reepithelialization, a transparent plastic sheet is usually placed over the wound and its margins are traced (Nascimento and Costa 2006; Amadeu et al. 2007). After digitization, the wound area can be measured (Otranto et al. 2010). Nascimento and Costa (2006), and Otranto et al. (2010) estimated wound reepithelization in rats by the difference between the total lesion area and the wound area still uncovered with epidermis. Similarly, dos Santos Rosa et al. (2014) evaluated wound contraction and reepithelialization in mice by tracing the margins of the total wound area and nonreepithelialized wound area using a transparent plastic sheet.

Scardino et al. (1999) traced (on sterile transparent polyethylene sheets) the total wound area, the area of epithelium on the wound and the area of unepithelialized granulation tissue in the wound centre in Beagle dogs on the day of surgery and several postoperative days, aiming to calculate the percentage of wound contraction, the percentage of epithelialization and the percentage of total wound healing compared to the original wound. The percentage of wound contraction can be measured using the formula of Ramanathan et al. (2017): wound contraction $(\%)=$ [wound area $($ day 0$)-$ wound area $($ day $n) /$ wound area $($ day 0$)$ ] $\times 100-3$. McDaniel et al. (2008) defined wound healing as the advance of the wound margins toward the wound centre and measured a daily area yet to be healed by a noncontact method using an orientation card of known dimensions placed next to the wound sites, single digital camera photogrammetry (SCP), and a wound measurement software.

Amadeu et al. (2003) elaborated a stereological method of Baddeley et al. (1986) and Gundersen et al. (1988), which enables to obtain information about three-dimensional structures based on observations made in two dimensional structures. The authors (Amadeu et al. 2003) calibrated on the monitor the test system with cycloids, the minor axes of cycloids being arranged in parallel with the defined vertical axis. Skin fields were analysed in papillary and reticular dermis for surface density, length density and volume density for vessels and myofibroblasts using videomicroscopic system.

\section{Tensile strength}

For tensile strength measurements, not an excision, but an incision model of wound is usually used (Sathyanarayanan et al. 2017). The healed wound tissues are removed, harvested tissues are trimmed into strips of suitable length and width (with the original wound lying lengthwise in the centre of the sample), and apart from tensile strength (in $\mathrm{MPa}$ ), a percentage of elongation at break (\%) is usually measured (Ramanathan et al. 
2017). Tensile strength increment indicates improved wound healing (Sathyanarayanan et al. 2017).

Local strain analysis at a physiological level of tension using a multiscale mechanics approach to the characterization of murine excisional wounds subjected to uniaxial tensile loading showed the presence of two distinct regions within the wound in an experiment of Pensalfini et al. (2018): a very compliant peripheral cushion and a core area undergoing modest deformation. The authors reported negligible engagement of collagen located in the centre of a 7-day old wound with the compliant cushion at the wound periphery protecting the newly-formed tissue from excessive deformation at this phase; the early remodelling phase was characterized by a restored mechanical connection between the far field and the wound centre.

\section{Assessment of collagen synthesis}

The standard procedure for an estimation of the extent of collagenesis is based on the determination of hydroxyproline (Caetano et al. 2016). Hydroxyproline is produced post-translationally by hydroxylation of the amino acid proline and since this hydroxylation is almost entirely specific to the collagen protein, L-hydroxyproline (especially T4L- hydroxyproline) is an important marker for directly measuring the content of collagen in biological samples (Watanabe et al. 2015). Hydroxyproline comprises approximately $13.5 \%$ of the mammalian collagen (Gorres and Raines 2010).

Hydroxyproline is usually determined spectrophotometrically after the acid hydrolysis of the sample (Otranto et al. 2010; dos Santos Rosa et al. 2014). Morphometric analysis by Caetano et al. (2016) can also be used as a simple, rapid and low-cost technology for evaluating total collagen in cutaneous wound specimens. Nevertheless, a biochemical hydroxyproline assay is still frequently used (Gercek et al. 2007; Ramanathan et al. 2017; Sathyanarayanan et al. 2017).

The method of Lin and Kuan (2010) includes chromophore formation without solvent transfers that allows the analysis of multiple specimens with excellent sensitivity, high specificity at low cost and shorter analysis time. The procedure of Colgrave et al. (2008) utilizes a highly selective and sensitive method of multiple reaction monitoring by mass spectrometry. Watanabe et al. (2015) developed a procedure using coupling systems with metabolic enzymes of the T4L- and T3L-hydroxyproline pathways from microorganisms and reported a successful hydroxyproline estimation within a broad range of wavelengths using a spectrophotometric assay, the results being consistent with those determined by high performance liquid chromatography.

It should be concluded however, that the hydroxyproline content reported in different experiments evaluating the effect of the same active substance (EPA, DHA) in a comparable phase of wound healing and applying various above-mentioned methods of hydroxyproline determination sometimes differs as much as by one order of magnitude and a comparison of the data obtained by different methods should therefore be taken with caution.

\section{Histopathology and immunohistochemistry (IHC) of cutaneous wound healing}

Periodically collected samples of the granulation tissue from wound sites using predominantly a rodent model are usually evaluated (Nascimento and Costa 2006; Gercek et al. 2007; Otranto et al. 2010; dos Santos Rosa et al. 2014; Ramanathan et al. 2017; Sathyanarayanan et al. 2017; Zhou et al. 2017). As far as histological preparations are concerned, samples of the healing tissue including ca $2 \mathrm{~mm}$ of skin surrounding the wound are usually taken, fixed in $10 \%$ buffered formalin, dehydrated by a gradual alcohol series, cleared in xylene, embedded in paraffin blocks, sectioned into a size of (usually) $5 \mu \mathrm{m}$ thickness, stained with haematoxylin-eosin (H\&E) and observed 
under light microscopy. The evaluated markers are usually inflammatory cell infiltration, neovascularization (angiogenesis), fibroblast proliferation and epidermal remodelling (Gercek et al. 2007; Sathyanarayanan et al. 2017). Apart from H\&E staining, Sirius red and toluidine blue can be used for evaluation of collagen fibres and mast cells, respectively (Nascimento and Costa 2006).

Regarding IHC assessment, paraffin embedded tissue sections, xylene-rehydrated and treated in a series of ethanol solutions are usually used (Ramanathan et al. 2017). If the detection of the searched-for protein is based on a reaction catalysed by a peroxidase (conjugated with a secondary antibody), endogenous peroxidases must be quenched beforehand by submersing the treated sections in a solution of $\mathrm{H}_{2} \mathrm{O}_{2}$ in methanol (Gercek et al. 2007). Rabbit polyclonal IgG (Ramanathan et al. 2017) or mouse monoclonal antibody (Otranto et al. 2010; dos Santos Rosa et al. 2014) are usually used as a primary antibody for immunostaining. Goat anti-rabbit antibody (Zhou et al. 2017) and biotinylated anti-rat antibody (dos Santos Rosa et al. 2014) are frequently applied secondary antibodies in this context. The last mentioned authors (dos Santos Rosa et al. 2014) also used an anti-mouse secondary antibody conjugated with Alexa Fluor 647 for the detection of epithelial cadherin (E-cadherin) when evaluating cutaneous wound healing in mice.

The following antigenic markers are most frequently detected by the semi-quantitative IHC procedures: alpha smooth muscle actin ( $\alpha$-SMA) (Zhou et al. 2017), e.g. in the blood vessel wall (Otranto et al. 2010) or in myofibroblasts (Nascimento and Costa 2006; dos Santos Rosa et al. 2014); myeloperoxidase-positive neutrophils, F4/80-positive macrophages, 4-hydroxynoneal-positive cells and E-cadherin (dos Santos Rosa et al. 2014; see above). Other proteins, detected by IHC, with an important informative value regarding evaluation of cutaneous wound healing, include cyclooxygenase-2 (COX-2) and inducible NO synthase (iNOS; Ramanathan et al. 2017) or transforming growth factor beta (TGF- $\beta$ ) and platelet-derived growth factor (PDGF; Gercek et al. 2007).

\section{Genomic and proteomic markers of wound healing}

Expression of the genes that are active during the process of wound healing is usually evaluated by quantitative polymerase chain reaction (q-RT-PCR) after extraction of total RNA by (usually) guanidinium thiocyanate-phenol-chloroform extraction (TRIzol reagent; Figueroa et al. 2012) and a reverse transcription of messenger RNA (mRNA) to complementary DNA (cDNA; Turk et al. 2013; Ramanathan et al. 2017).

Expression of the following genes was mostly quantified in experiments evaluating the effect of EPA/DHA (fish oil) on wound healing: vascular endothelial growth factor $(V E G F)$, epidermal growth factor $(E G F)$ and transforming growth factor beta (TGFB; Ramanathan et al. 2017); TGFB1, cyclooxygenase 2 (COX2) and $\alpha$-SMA (Zhou et al. 2017); protein kinase B (Akt) and cyclic AMP responsive element binding protein (CREB; Figueroa et al. 2012); $A C T A$ (coding for alpha skeletal muscle actin), COL1A1 (type I collagen), VIM (coding for vimentin, type III intermediate filament protein, marker of mesenchymal derived cells), $C D H$ (coding for E-cadherin, cell adhesion molecule enabling formation of adherens junctions to bind cells with each other) and Snail (coding for zinc finger protein SNAI1, transcription factor promoting repression of E-cadherin to regulate epithelial-to-mesenchymal transition; Pastor-Clerigues et al. 2014); G-protein coupled receptor GPR120 (Arantes et al. 2016).

Due to the fact that inflammation is an important phase of wound healing, some authors quantified expression of the genes coding for pertinent cytokines/chemokines: interleukin (IL)-1 $\beta$, IL-4, IL-6, IL-10, IL-13, IL-22, TGF- $\beta$, interferon gamma (IFN $\gamma$ ), tumour necrosis factor alpha $(\mathrm{TNF} \alpha)$ and monocyte chemoattractant protein 1 (MCP1; Turk et al. 2013); TNF- $\alpha$, IL-1 $\beta$ and IL-6 (Weldon et al. 2007). Glyceraldehyde 3-phosphate 
dehydrogenase (GAPDH) and $\beta$-actin are usually used as normalization ("housekeeping") genes (Figueroa et al. 2012).

As far as expression on the protein level is concerned, Western blot procedure (including cell lysis by Triton X-100 and EDTA, inhibition of proteases, solubilisation with sodium dodecyl sulphate [SDS] and polyacrylamide gel electrophoresis [PAGE]; Turk et al. 2013) is usually applied (Chen et al. 2012; Chao et al. 2014; dos Santos Rosa et al. 2014).

Within experiments evaluating effect of PUFA n-3 on wound healing in general (not only skin lesions), following proteins were quantified using Western blot analysis: VEGF-A, VGEF receptor 2 (VEGFR2) and E-cadherin (dos Santos Rosa et al. 2014); COX-2, TGF- $\beta 1$ and SMAD2/3 (mothers against decapentaplegic homolog 2/3, signal transducers for TGF- $\beta 1$ receptors; Zhou et al. 2017); $\alpha$-SMA, SMAD2/3, phospho-SMAD2/3, ERK (extracellular signal-related kinase), phospho-ERK and CD68 (Cluster of Differentiation 68 , protein strongly expressed in monocytes and circulating macrophages, and also by tissue macrophages) and GGT (gamma-glutamyltransferase; Chen et al. 2012); EGFR (epidermal growth factor receptor), phospho-EGFR, PLC (phospholipase C) $\gamma 1$ and phospho-PLC $\gamma 1$ (Turk et al. 2013); ERK1/2, phospho-ERK1/2 and eNOS (endothelial NO synthase; Chao et al. 2014); phospho-SMAD3, phospho-ERK1/2, phospho-Akt and nuclear $\beta$-catenin (Pastor-Clerigues et al. 2014); cytoplasmic and nuclear p65 (nuclear factor NF-kappa B p65 subunit) and IкB- $\alpha$ (nuclear factor of kappa light polypeptide gene enhancer in B-cells inhibitor-alpha, protein inhibiting the NF- $\mathrm{B}$ transcription factor; Weldon et al. 2007).

\section{Fish oil (eicosapentaenoic and docosahexaenoic acid) in wound healing}

\section{Dietary administration}

As far as cutaneous wound healing is concerned, high fat diet, irrespective of the type of fat/oil, delays wound contraction and reepithelialization, increases the inflammatory infiltrate, delays myofibroblastic differentiation, collagen deposition, epithelial and connective tissue cell proliferation and angiogenesis (Nascimento and Costa 2006); the authors reported negative effects of a high-fat diet on rat cutaneous wound healing especially due to the prolongation of the inflammatory phase.

Otranto et al. (2010) compared the effect of different edible oils (sunflower, linseed, fish) on cutaneous wound healing in rats and concluded that all edible oils delayed wound closure, and affected the inflammatory infiltrate and collagen deposition. However, in the fish oil group, more abundant inflammatory cells, high density of dilated blood vessels and high density of collagen fibres were found; the best results were achieved with sunflower oil. The authors (Otranto et al. 2010) are cautious regarding fish oil due to the increase in collagen synthesis possibly resulting in excessive scar tissue. Fish oil was also evaluated as a less suitable in comparison with olive oil in application to healing of excisional lesions in (rotationally) stressed mice in a study by dos Santos Rosa et al. (2014). Olive oil, but not fish oil, inhibited stress-induced reduction in wound contraction, reepithelialization, hydroxyproline levels and blood vessel density; fish oil (contrary to olive oil) was not able to reverse stress-induced increases in VEGF expression and number of macrophages and neutrophils.

On the other hand, Scardino et al. (1999), when comparing menhaden fish oil (with PUFA n-6/n-3 ratio of 0.3 ) and a control oil (PUFA n-6/n-3 ratio of 7.7) in wound healing in Beagle dogs, found in the fish oil group at five days post-surgery significantly less epithelialization of open wounds, less oedema in sutured wounds, and tendencies of less tissue perfusion, lower level of prostaglandin E2 and negative wound contraction in open wounds. Therefore, the authors concluded that PUFA n-3 does not appear to have an 
outstanding long-term effect on wound healing due to (among other things) the lack of granulation tissue over which the epithelium would advance.

Several authors evaluated the efficiency of PUFA n-3 in healing of injuries different than cutaneous excisions/incisions. In cholestatic liver injury (induced by bile duct ligation, BLD) in rats, chronic DHA supplementation alleviated BLD-induced increase of TGF- $\beta 1$, IL- $1 \beta$, connective tissue growth factor and collagen expression (Chen et al. 2012); DHA had an antifibrotic effect: decreased $\alpha$-SMA-positive matrix producing cells and Smad 2/3 activity (i.e. fibrogenic potential of TGF- $\beta 1$ ). DHA also decreased leukocyte accumulation and NF- $\mathrm{\kappa B}$ activation. The authors concluded that DHA shows multifactorial hepatoprotective, anti-oxidative, anti-inflammatory and anti-fibrotic effect.

According to Coelho de Castilho et al. (2015), preoperative supplementation with PUFA n-3 in rats was associated with increased collagen deposition of the type I fibres in colonic anastomoses on the $5^{\text {th }}$ postoperative day; no differences in the tensile strength or collagen maturation index in comparison with control were found. Dietary supplementation with PUFA n-3 (in combination with ascorbic acid) improved (by additive action) the healing of ischemic colonic anastomoses in rats in a study by Ekçi et al. (2011). On the other hand, Drzymała-Czyż et al. (2012) reported higher intensity of inflammation and tissue expression of IL-1 $\alpha$ and IL-10 in the DHA-fed group of rats that underwent restorative proctocolectomy (induced pouchitis) in comparison with control.

Based on the results of Figueroa et al. (2012), DHA protected and functionally improved the spinal cord injury in rats. A DHA pretreatment increased the percentage of white matter sparing (axonal preservation), and increased the survival of $\mathrm{NG}^{+}, \mathrm{APC}^{+}$and $\mathrm{NeuN}^{+}$cells in the ventrolateral funiculus, dorsal corticospinal tract and ventral horns, despite the lack of inhibition of inflammatory markers for monocytes/macrophages and astrocytes. DHA also increased the levels of Akt and CREB mRNA and protein. Figueroa et al. (2012) therefore concluded that DHA-mediated activation of pro-survival/anti-apoptotic pathways may be independent of its anti-inflammatory effects.

DHA decreased inflammation and joint destruction in mice with collagen-induced arthritis in an experiment of Olson et al. (2013); DHA, but not a mixture of DHA/EPA, decreased arthritis severity and joint damage, decreased level of the anti-collagen (CII) antibodies, downregulated IL-1 $\beta$, IFN- $\gamma$ and upregulated protective IL-10. According to the authors, the dietary administration of DHA is a useful intervention strategy against inflammatory arthritis.

\section{Parenteral application}

Arantes et al. (2016) applied a $30 \mu \mathrm{M}$ DHA solution once a day as a topical treatment of a cutaneous excision in male Wistar rats. DHA significantly accelerated wound healing, promoted a reduction of IL- $1 \beta$ expression and increased expression of IL- 6 and TGF- $\beta$; involved in this process was the molecular activation of GPR 120. However, in comparison with control, fish oil emulsion applied in rats on cutaneous wound healing showed a lower hydroxyproline level, shallower wounds, worse histologic score and lower expression score of TGF- $\beta$ and PDGF-AA (Gercek et al. 2007); nevertheless, according to the authors, PUFA n-3 does not seem to have adverse effects on wound healing.

Hall et al. (2012) applied EPA or DHA intravenously in rats that underwent compression spinal cord injury (SCI). DHA, but not EPA, decreased neutrophil numbers in some areas of the injured epicentre and decreased plasma level of C-reactive protein. However, neither DHA nor EPA reversed the inflammatory response in the liver caused by the SCI, and neither was able to return to the control values the increased levels of IL- 6 , IL-1 $\beta$ and TNF- $\alpha$ in the SCI epicentre at $4 \mathrm{~h}$ after injury; therefore, the neuroprotective effects of LC PUFA n-3 in rat compression SCI can only partly be attributed to the reduction of early inflammatory events after injury. 


\section{Comparative results of the in vitro studies}

DHA inhibited the development of non-small cell tumours (in the non-small cell lung cancer cell line A 459) through a ROS-mediated inactivation of the PI3K/Akt signalling pathway (Yin et al. 2017). When tested on the mouse immortalized colonocyte model, both EPA and DHA delayed (during the early response to intestinal wounding) the activation of key wound-healing processes in the colon (Turk et al. 2013) due to the reduced EGFR ligand-induced receptor activation, which was associated with a reduction in a downstream activation of cytoskeletal remodelling proteins. Chao et al. (2014) found that DHA inhibited VEGF-induced cell migration in a culture of umbilical vein endothelial cells, which implies that the effect of DHA on angiogenesis and wound repair is at least partly by virtue of its attenuation of cell migration.

The effect of a fish oil commercial emulsion on inflammatory and pro-fibrotic liver markers was tested in culture supernatants of monocytes using a liver epithelial-tomesenchymal transition (EMT) induced by TGF- $\beta 1$ (Pastor-Clerigues et al. 2014). Monocytes stimulated in vitro with LPS induced a strong inflammatory response that was suppressed by a commercial emulsion containing $100 \%$ of fish oil. This emulsion also suppressed the TGF- $\beta 1$-induced EMT, contrary to the control soybean oil emulsion (which enhanced EMT).

Pretreatment with $100 \mu \mathrm{M}$ EPA or DHA decreased the amount of TNF- $\alpha$, IL-1 $\beta$ and IL-6 proteins in the THP-1 monocyte-derived macrophages stimulated with LPS (Weldon et al. 2007). Both EPA and DHA also decreased TNF- $\alpha$, IL-1 $\beta$ and IL- 6 mRNA expression, but DHA was more potent. Moreover, both EPA and DHA downregulated LPS-induced NF$\kappa \mathrm{B} / \mathrm{DNA}$ binding in the THP-1 macrophages, but only DHA decreased macrophage nuclear p65 expression and increased cytoplasmic IкB- $\alpha$ expression. The authors (Weldon et al. 2007) concluded that DHA was more effective than EPA in alleviating LPS-induced, partly $\mathrm{NF}-\kappa \mathrm{B}-$ mediated, pro-inflammatory cytokine production in macrophages.

\section{Summary}

Based on the results of the pertinent experiments, effects of fish oil or its active constituents EPA/DHA on wound healing are very inconsistent. The amount of hydroxyproline and collagen deposition was increased in some experiments, but decreased in other ones. Regarding inflammatory cells, the numbers of macrophages and neutrophils were increased by fish oil, but the numbers of leukocytes were decreased by DHA. DHA either increased or decreased inflammation after injury; EPA/DHA were not able to reverse the inflammatory response and their protective effects seem to be only partly attributed to the reduction of the early inflammatory events after injury. As far as particular pro- and antiinflammatory markers are concerned, DHA both increased and decreased TGF- $\beta$; TGF- $\beta$ was also decreased by fish oil. On the other hand, it seems that DHA consistently decreases IL- $1 \beta$ and TNF- $\alpha$, and is able to increase IL-10. Therefore, it is not surprising that DHA likely mediates the activation of pro-survival/anti-apoptotic pathways independently of its anti-inflammatory effects.

Inconsistency also regards the wound healing rate: DHA both accelerated and delayed the wound healing processes in similar experiments. Finally, it follows from the results of some experiments that DHA is more effective in wound healing than EPA.

Conclusions of the above-mentioned literature data, including recommendations for future experiments can be formulated as follows: 1) The effects of long-chain polyunsaturated fatty acids (LC-PUFA) n-3 on wound healing tested on rodents are very inconsistent. 2) Regarding mammalian skin morphology, an optimal model for wound healing in humans is a pig (Seaton et al. 2015); however, an application of LC-PUFA n-3 using a porcine model is not described in available literature. 3) Due to the unconvincing effects of dietary 
LC-PUFA n-3 in physiological concentrations in in vivo experiments, it would be interesting to try to apply these fatty acids topically at higher concentrations in combination with nanoparticles; using nanoparticles in wound healing is extensive (Rajendran et al. 2018), but a description of their effects in combination with LC-PUFA n-3 is missing altogether in the given context. 4) A cutting-edge method of MALDI (matrix-assisted-laser-desorptionionization) with a detection of time-of-flight (TOF) can be used e.g. in a quantification of collagen in the tissues (Nimptsch et al. 2011), but again, its application in the evaluation of cutaneous wound healing in a porcine model using a combination of LC-PUFA n-3 and nanoparticles would be completely original.

\section{Acknowledgement}

The study was supported by the Internal Grant Agency of the Mendel University in Brno, project No. TP3/2017.

\section{References}

Amadeu T, Braune A, Mandarim-de-Lacerda C, Porto LC, Desmoulière A, Costa A 2003: Vascularization pattern in hyperthrophic scars and keloids: A stereological analysis. Pathol Res Pract 199: 469-473

Amadeu TP, Seabra AB, de Oliveira MG, Costa AM 2007: S-nitrosoglutathione-containing Hydrogel accelerates rat cutaneous wound repair. J Eur Acad Dermatol Venereol 21: 629-637

Arai T, Kim HJ, Chiba H, Matsumoto A 2009: Anti-obesity effect of fish oil and fish oil-fenofibrate combination in female KK mice. J Atheroscler Thromb 16: 674-683

Arantes EL, Dragano N, Ramalho A, Vitorino D, de Souza GF, Lima MH, Velloso LA, Araújo EP 2016: Topical docosahexaenoic acid (DHA) accelerates skin wound healing in rats and activates GPR120. Biol Res Nutr 18: 411-419

Arita M, Yoshida M, Hong S, Tjonahen E, Glickman JN, Petasis NA, Blumberg RS, Serhan CN 2005: Resolvin E1, an endogenous lipid mediator derived from omega-3 eicosapentaenoic acid, protect against 2,4,6-trinitrobenzene sulfonic acid-induced colitis. Proc Nat Acad Sci 102: 7671-7676

Baddeley AJ, Gundersen HJG, Crus-Orive LM 1986: Estimation of surface area from vertical sections. J Microsc 142: $259-276$

Barberger-Gateau P, Letenneur L, Deschamps V, Peres K, Dartigues JF, Renaud S 2002: Fish, meat and risk of dementia: cohort study. Brit Med J 325: 932-933

Caetano GF, Fronza M, Leite MN, Gomes A, Cipriani Frade MA 2016: Comparison of collagen content in skin wounds evaluated by biochemical assay and by computer-aided histomorphometric analysis. Pharm Biol 54: 2555-2559

Campos AC, Groth AK, Branco AB 2008: Assessment and nutritional aspects of wound healing. Curr Opin Clin Nutr Metab Care 11: 281-288

Chao CY, Lii CK, Ye SY, Li CC, Lu CY, Lin AH, Liu KL, Chen HW 2014: Docosahexaenoic acid inhibits vascular endothelial growth factor (VEGF)-induced cell migration via the GPR120/PP2A/ERK1/2/eNOS signaling pathway in human umbilical vein endothelial cells. J Agric Food Chem 62: 4152-4158

Chen WY, Lin SY, Pan HC, Liao SL, Chuang YH, Yen YJ, Lin SY, Chen CJ 2012: Beneficial effect of docosahexaenoic acid on cholestatic liver injury in rats. J Nutr Biochem 23: 252-264

Coelho de Castilho TJ, Campos ACL, de Souza Leite Mello EV 2015: Effect of omega-3 fatty acid in the healing process of colonic anastomosis in rats. ABCD Arq Bras Cir Dig 28: 258-261

Colgrave ML, Allingham PG, Jones A 2008: Hydroxyproline quantification for the estimation of collagen in tissue using multiple reaction monitoring mass spectrometry. J Chromatogr A 1212: 150-153

Cranmer-Byng MM, Liddle DM, De Boer AA, Monk JM, Robinson LE 2015: Pro-inflammatory effects of arachidonic acid in a lipopolysaccharide-induced inflammatory microenvironment in 3T3-L1 adipocytes in vitro. Appl Physiol Nutr Metab 40: 142-154

Das U 2006: Essential fatty acids - A review. Curr Pharm Biotech 7: 467-48

De Boer AA, Monk JM Robinson LE 2014: Docosahexaenoic acid decreases pro-inflammatory mediators in an in vitro murine adipocyte macrophage co-culture model. PLoS One 9: e85037

Dinarello CA 2010: Anti-inflammatory agents: present and future. Cell 140: 935-950

dos Santos Rosa A, Bandeira LG, Monte-Alto-Costa A, Romana-Souza B 2014: Supplementation with olive oil, but not fish oil, improves cutaneous wound healing in stressed mice. Wound Rep Reg 22: 537-547

Drzymała-Czyż, Banasiewicz T, Tubacka M, Trasiuk-Rusek A, Majewski P, Drews M, Walkowiak J 2012: Discrepancy between clinical and histological effects of DHA supplementation in a rat model of pouchitis. Folia Histochem Cytobiol 50: 125-129

Ekçi B, Karabicak I, Atukeren P, Altinlio E, Tomaoglu K, Tasci I 2011: The effect of omega-3 fatty acid and ascorbic acid on healing of ischemic colon anastomoses. Ann Ital Chir 82: 475-479 
Figueroa JD, Cordero K, Baldeosingh K, Torrado AI, Walker RL, Miranda JD, De Leon M 2012: Docosahexaenoic acid pretreatment confers protection and functional improvements after acute spinal cord injury in adult rats. J Neurotrauma 29: 551-566

Flock MR, Rogers CJ, Sandeep Prabhu K Kris-Etherton PM 2013: Immunometabolic role of long-chain omega-3 fatty acids in obesity-induced inflammation. Diabetes-Metab Res Rev 29: 431-445

Galiano RD, Michael JV, Dobryanski M, Levine JP, Gurtner DC 2004: Quantitative and reproducible murine model of excisional wound healing. Wound Repair Regener 12: 485-492

Gercek A, Yildirim O, Konya D, Bozkurt S, Ozgen S, Kilic T, Sav A, Pamir N 2007: Effects of parenteral fish-oil emulsion (Omegaven) on cutaneous wound healing in rats treated with dexamethasone. J Parenter Enter Nutr 31: $161-166$

Givens DI, Gibbs RA 2008: Current intakes of EPA and DHA in European populations and the potential of animal-derived foods to increase them. Proc Nutr Soc 67: 273-280

Gorres KL, Raines RT 2010: Prolyl 4-hydroxylase. Crit Rev Biochem Mol Biol 45: 106-124

Guo S, Dipietro LA 2010: Factors affecting wound healing. J Dent Res 89: 219-229

Gundersen HJG, Bendtsen TF, Korbo L, Marcussen N, Moller A, Nielsen K, Nyengaard JR, Pakkenberg B, Sorensen FB, Vesterby A, West MJ 1988: Some new, simple and efficient stereological methods and their use in pathological research and diagnosis. APMIS 96: 379-394

Gurtner GC, Werner S, Barrandon Y, Longaker MT 2008: Wound repair and regeneration. Nature 453: $314-321$

Hall JCE, Priestley JV, Perry VH Michael-Titus AT 2012: Docosahexaenoic acid, but not eicosapentaenoic acid, reduces the early inflammatory response following compression spinal cord injury in the rat. $\mathrm{J}$ Neurochem 121: $738-750$

Jump DB 2008: N-3 polyunsaturated fatty acid regulation of hepatic gene transcription. Curr Opin Lipidol 19: 242-247

Komprda T 2012: Eicosapentaenoic and docosahexaenoic acids as inflammation-modulating and lipid homeostasis influencing nutraceuticals: A review. J Funct Foods 4: 25-38

Komprda T, Ondráčková P, Vícenová M, Rozíková V, Procházková N, Levá L, Faldyna M 2018: Effect of dietary fish oil on selected inflammatory markers in pigs. Animal 12: 2098-2107

Komprda T, Sládek Z, Škultéty O, Křižzová S, Rozíková V, Němcová B, Šustrová B, Valová M 2016: Effect of dietary Schizochytrium microalga oil on selected markers of low-grade inflammation in rats. J Anim Physiol Anim Nutr 100: 1169-1178

Kostadinova R, Wahli W, Michalik L 2005: PPARs in disease: Control mechanisms of inflammation. Curr Med Chem 12: 2413-2446

Lin Y-K, Kuan C-Y 2010: Development of 4-hydroxyproline analysis kit and its application to collagen quantification. Food Chem 119: 1271-1277

Liu YH, Li XY, Chen CY, Zhang HM Kang JX 2015: Omega-3 fatty acid intervention supresses lipopolysacharideinduced inflammation and weight loss in mice. Mar Drugs 13: 1026-1036

Liu YL, Gong LM, Li DF, Feng ZY, Zhao LD Dong T 2003: Effects of fish oil on lymphocyte proliferation, cytokine production and intracellular signalling in weanling pigs. Arch Anim Nutr 57: 151-165

McDaniel J, Belury M, Ahijevych K, Blakely W 2008: Omega-3 fatty acids effect on wound healing. Wound Rep Reg 16: 337-345

Nakamura MT, Cheon Y, Li Y, Nara TY 2004: Mechanisms of regulation of gene expression by fatty acids. Lipids 39: $1077-1083$

Nascimento AP, Costa AM 2006: Overweight induced by high-fat diet delays rat cutaneous wound healing. Br J Nutr 96: 1069-1077

Nguyen DT, Orgill DP, Murphy GP 2009: The pathophysiologic basis for wound healing and cutaneous regeneration. In: Orgill DP, Blanco C (Eds): Biomaterials for Treating Skin Loss. Elsevier, pp. 25-57

Nimptsch A, Schibur S, Ihling C, Sinz, A, Riemer T, Huster D, Schiller J 2011: Quantitative analysis of denatured collagen by collagenase digestion and subsequent MALDI-TOF mass spectrometry. Cell Tissue Res 343: 605-617

Oliver E, McGillicudy F, Phillips C, Toomey S Roche HM 2010: The role of inflammation and macrophage accumulation in development of the obesity-induced type 2 diabetes mellitus and the possible therapeutic effects of long-chain n-3 PUFA. Proc Nutr Soc 69: 232-243

Olson MV, Liu YC, Dangi B, Zimmer JP, Salem N, Nauroth JM 2013: Docosahexaenoic acid reduces inflammation and joint destruction in mice with collagen-induced arthritis. Inflamm Res 62: 1003-1013

Otranto M, Do Nascimento AP, Monte-Alto-Costa A 2010: Effects of supplementation with different edible oils on cutaneous wound healing. Wound Repair Regen 18: 629-636

Pastor-Clerigues A, Marti-Bonmati E, Milara J, Almudever P, Cortijo J 2014: Anti-inflammatory and anti-fibrotic profile of fish oil emulsions used in parenteral nutrition-associated liver disease. PLoS One 9: e115404

Pensalfini M, Haertel E, Hopf R, Wietecha M, Werner S, Mazza E 2018: The mechanical fingerprint of murine excisional wounds. Acta Biomater 65: 226-236

Rajendran NK, Kumar SSD, Houreld NN, Abrahamse H 2018: A review on nanoparticle based treatment for wound healing. J Drug Deliv Sci Tec 44: 421-430

Ramanathan G, Muthukumar T, Sivagnanam UT 2017: In vivo efficiency of the collagen nanofibrous scaffold and their effect on growth factors and pro-inflammatory cytokines in wound healing. Eur J Pharmacol 814: 45-55 
Romacho T, Glosse P, Richter I, Elsen M, Schoemaker MH, van Tol EA, Eckel J 2015: Nutritional ingredients modulate adipokine secretion and inflammation in human primary adipocytes. Nutrients 7: 865-886

Ruxton CHS, Calder PC, Reed SC, Simpson MJA 2005: The impact of LC n-3 PUFA on human health. Nutr Res Rev 18: 113-129

Sathyanarayanan S, Muniyandi K, George E, Sivaraj D, Sasidharan SP, Thangaraj P 2017: Chemical profiling of Pterolobium hexapetalum leaves by HPLC analysis and its productive wound healing activities in rats. Biomed Pharmacother 95: 287-297

Scardino MS, Swaim SF, Sartin EA, Hoffman CE, Oglivie GK, Hanson RA, Coolman SL, Davenport DJ 1999: The effects of omega-3 fatty acid diet enrichment on wound healing. Vet Dermatol 10: 283-290

Schmitz G, Ecker J 2008: The opposing effects of n-3 and n-6 fatty acids. Prog Lipid Res 47: 147-155

Seaton M, Hocking A, Gibran NS 2015: Porcine models of cutaneous wound healing. ILAR J 56: 127-138

Serhan CN and Savill J 2005: Resolution of inflammation: the beginning programs the end. Nat Immunol 6: 1191-1197

Serhan CN, Dalli J, Colas RA, Winkler JW, Chiang N 2015: Protectins and maresins: New pro-resolving families of mediators in acute inflammation and resolution bioactive metabolome. Biochim Biophys Acta 1851: $397-413$

Siriwardhana N, Kalupahana NS, Cekanova M, LeMieux M, Greer B Moustaid-Moussa N 2013: Modulation of adipose tissue inflammation by bioactive food compounds. J Nutr Biochem 24: 613-623

Turk HF, Monk JM, Fan Y-Y, Callaway ES, Weeks B, Chapkin RS 2013: Inhibitory effects of omega-3 fatty acids on injury-induced epidermal growth factor receptor transactivation contribute to delayed wound healing. Am J Physiol Cell Physiol 304: C905-C917

van Gelder BM, Tijhuis M, Kalmijn S, Kromhout D 2007: Fish consumption, n-3 fatty acids, and subsequent 5-y cognitive decline in elderly men: the Zutphen Elderly Study. Am J Clin Nutr 85: 1142-1147

Velnar T, Bailey T, Smrkolj V 2009: The wound healing proces: an overview of the cellular and molecular mechanisms. J Int Med Res 37: 1528-1542

Vigerust NF, Bjørndal B, Bohov P, Brattelid T, Svardal A Berge RK 2013: Krill oil versus fish oil in modulation of inflammation and lipid metabolism in mice transgenic for TNF- $\alpha$. Eur J Nutr 52: 1315-1325

Watanabe S, Hiraoka Y, Endo S, Tanimoto Y, Tozawa Y, Watanabe Y 2015: An enzymatyic method to estimate the content of L-hydroxyproline. J Biotechnol 199: 9-16

Weldon SM, Mullen AC Loscher CE, Hurley LA, Roche HM 2007: Docosahexaenoic acid induces an antiinflammatory profile in lipopolysaccharide-stimulated human THP-1 macrophages more effectively than eicosapentaenoic acid. J Nutr Biochem 18: 250-258

Yin Y, Sui C, Meng F, Ma P, Jiang Y 2017: The omega-3 polyunsaturated fatty acid docosahexaenoic acid inhibits proliferation and progression of non-small cell lung cancer cells through the reactive oxygen species-mediated inactivation of the PI3K/Akt pathway. Lipids Health Dis 16: 87

Zárate R, el Jaber-Vazdekis N, Tejera N, Pérez JA, Rodrígues C 2017: Significance of longchain polyunsaturated fatty acids in human health. Clin Trans Med 6: 25

Zhou J, Zhao Y, Simonenko V, Xu JJ, Liu K, Wang D, Shi J, Zhong T, Zhang L, Zeng J, Huang B, Tang S, Lu AY, Mixson AJ, Sun Y, Lu PY, Li Q 2017: Simultaneous silencing of TGF- $\beta 1$ and COX-2 reduces human skin hypertrophic scar through activation of fibroblast apoptosis. Oncotarget 8: 80651-80665 